\title{
BMJ Open Prevalence of sarcopenia and its associated factors in patients attending geriatric clinics in Vietnam: a cross- sectional study
}

\author{
Tam Ngoc Nguyen, ${ }^{1,2}$ Tu Ngoc Nguyen (1) , ${ }^{3}$ Anh Trung Nguyen, ${ }^{1,2}$ \\ Thanh Xuan Nguyen, ${ }^{1,2}$ Huong Thu Thi Nguyen, ${ }^{1,2}$ Thu Thi Hoai Nguyen, , ,2,4 \\ Thang Pham, ${ }^{1,2}$ Huyen Thanh Thi Vu (ID) ${ }^{1,5}$
}

To cite: Nguyen TN, Nguyen TN, Nguyen AT, et al. Prevalence of sarcopenia and its associated factors in patients attending geriatric clinics in Vietnam: a cross-sectional study. BMJ Open 2020;10:e037630. doi:10.1136/ bmjopen-2020-037630

- Prepublication history for this paper is available online To view these files, please visit the journal online (http://dx.doi. org/10.1136/bmjopen-2020037630).

Received 11 February 2020 Revised 17 June 2020 Accepted 03 August 2020

Check for updates

(C) Author(s) (or their employer(s)) 2020. Re-use permitted under CC BY-NC. No commercial re-use. See rights and permissions. Published by BMJ.

${ }^{1}$ Department of Geriatrics, Hanoi Medical University, Hanoi, Viet Nam

${ }^{2}$ Scientific Research

Department, National Geriatric Hospital, Hanoi, Vietnam ${ }^{3}$ Westmead Applied Research Centre, Faculty of Medicine and Health, The University of Sydney, Sydney, New South Wales,

Australia

${ }^{4}$ Dinh Tien Hoang Institute of Medicine, Hanoi, Viet Nam ${ }^{5}$ Hanoi Medical University Hospital, Ha Noi, Viet Nam

Correspondence to

Professor Huyen Thanh Thi Vu; vuthanhhuyen11@hmu.edu.vn

\section{ABSTRACT}

Objectives This study aims to investigate the prevalence of sarcopenia and its associated factors in patients attending geriatric clinics in Vietnam.

Design and setting A cross-sectional study was conducted in consecutive patients aged $\geq 60$ visiting outpatient clinics of the National Geriatric Hospital in Hanoi, Vietnam, from January 2018 to October 2018. Handgrip strength was measured with a hand dynamometer. Wholebody dual-energy $\mathrm{X}$-ray absorptiometry was applied to measure the appendicular skeletal muscle mass. Sarcopenia was defined by the criteria proposed by the Asian Working Group for Sarcopenia (AWGS 2019) and by the Foundation for the National Institutes of Health (FNIH) Sarcopenia Project.

Results There were 600 participants, mean age $70.0 \pm 8.0,60.8 \%$ female. The prevalence of sarcopenia was $54.7 \%$ according to AWGS 2019 criteria and $40.5 \%$ according to FNIH. In multivariate logistic regression, age (adjusted OR 1.08, 95\% Cl 1.05 to 1.11), male (adjusted OR $2.03,95 \% \mathrm{Cl} 1.29$ to 3.21), underweight (adjusted OR $2.32,95 \% \mathrm{Cl} 1.22$ to 4.41 ), being malnourished (adjusted OR $3.77,95 \% \mathrm{Cl} 1.19$ to 11.91 ), chronic lung diseases (adjusted OR 3.48, 95\% Cl 2.10 to 5.77) and lower physical activity were significantly associated with sarcopenia defined by AWGS 2019 criteria. With FNIH definition, the significantly associated factors were age (adjusted OR $1.07,95 \% \mathrm{Cl} 1.04$ to 1.11), male (adjusted OR 6.78, $95 \% \mathrm{Cl} 4.12$ to 11.17), low education (adjusted OR 2.15, $95 \% \mathrm{Cl} 1.27$ to 3.63 ), being malnourished (adjusted OR $3.35,95 \% \mathrm{Cl} 1.28$ to 8.76 ), chronic lung diseases (adjusted $\mathrm{OR} 2.58,95 \% \mathrm{Cl} 1.56$ to 4.28 ) and lower physical activity level.

Conclusion The prevalence of sarcopenia in patients attending geriatric clinics was high. Further studies are needed to examine the impact of sarcopenia on adverse outcomes in this population.

\section{INTRODUCTION}

Sarcopenia, defined as low muscle mass in combination with a decline of grip strength or in walking speed, can increase the risk of functional impairment, falls, mortality and healthcare expenditure. ${ }^{2}$ In 2016,

\section{Strengths and limitations of this study}

- This is the first study to examine the prevalence of sarcopenia and its associated factors in older patients attending geriatric clinics in Vietnam.

- This study contained a large sample of older patients with high-quality detailed clinical information and muscle mass was measured using dual energy $\mathrm{X}$-ray absorptiometry.

- This study was conducted at one geriatric hospital in Vietnam, which may not be representative for all older people in Vietnam.

sarcopenia was regconised as a disease by the WHO and received an International Classification of Diseases 10th Revision (ICD10) code (code ICD-10-CM: M62.84). ${ }^{3}$ The global prevalence of sarcopenia was around $6 \%-22 \%$ in people aged 65 years or older, which increased with age and varied across regions. ${ }^{4}$ In Asia, the reported prevalence of sarcopenia was around $10 \%-30 \%$ in community setting ${ }^{2}$ and was about $50 \%$ in hospitalised patients. ${ }^{5}{ }^{6}$ However, there is limited evidence on the prevalence of sarcopenia in older patients attending primary care and geriatric clinics. Older patients with multiple chronic diseases are at higher risk of having sarcopenia. ${ }^{7}$

The population in Vietnam, a country in Asia, is rapidly ageing. ${ }^{8}$ The percentage of people aged 60 or over is estimated to be $26.1 \%$ in the next 30 years. $^{8}$ Nearly $40 \%$ of older people in the community in Vietnam had multiple chronic diseases. ${ }^{9} 10$ Due to the ageing population, the population size, and the high prevalence of multimorbidity, the impact of sarcopenia in older people in Vietnam may be significant. However, the evidence of sarcopenia in older people attending outpatient clinics in Vietnam is 


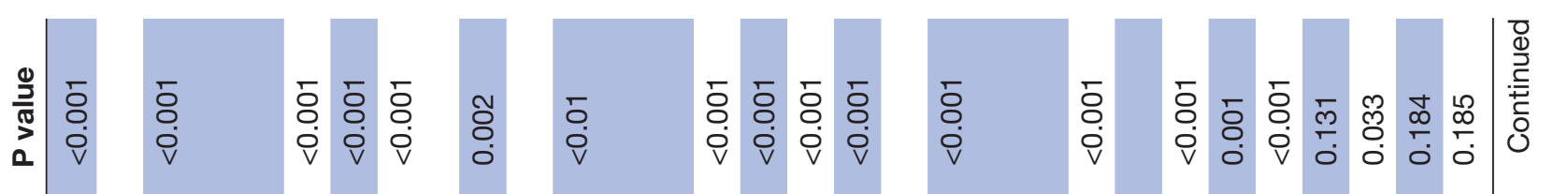

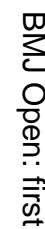

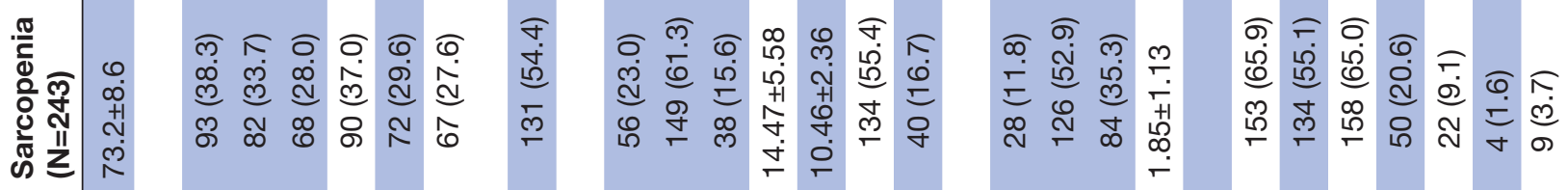

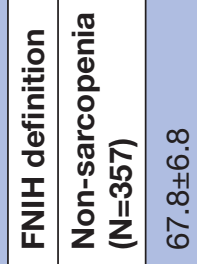

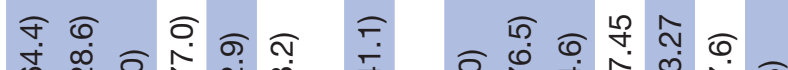

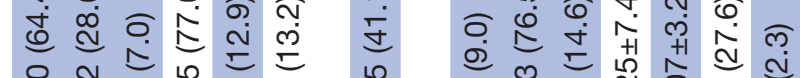

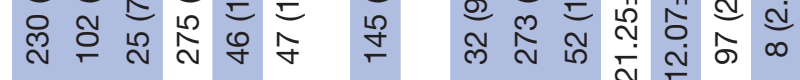

ติ

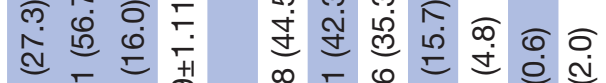

๙

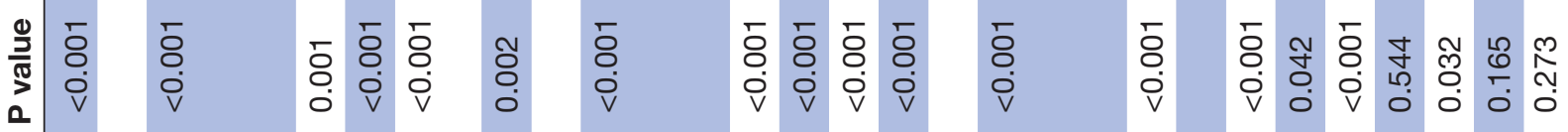

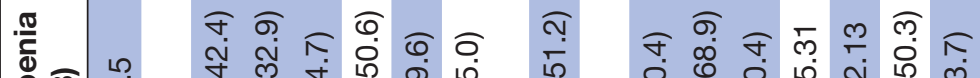

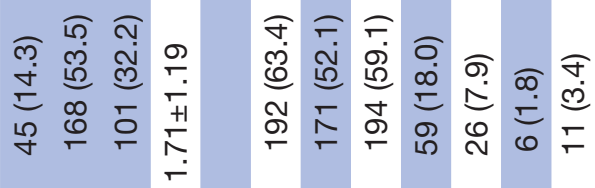

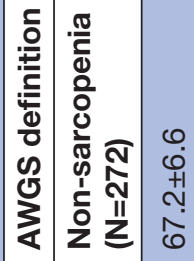

ब⿳亠丷⿵冂丶

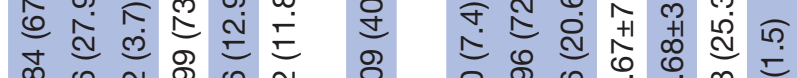

茂
กิ

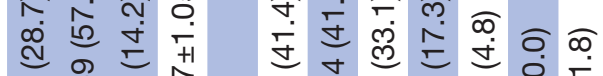

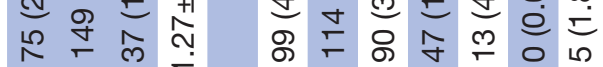

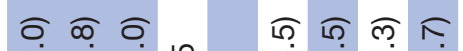

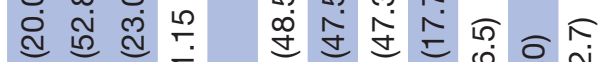

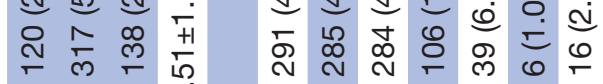

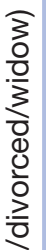

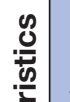

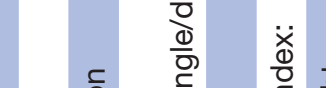
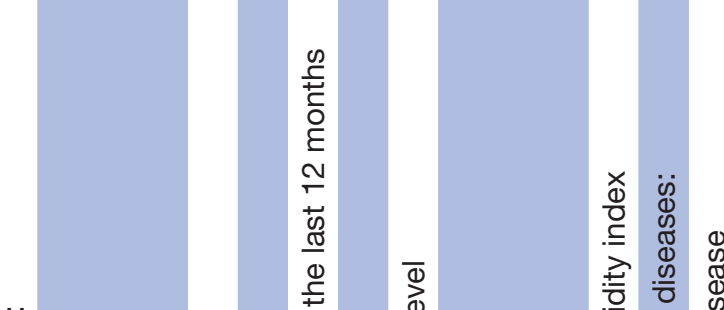

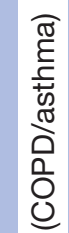

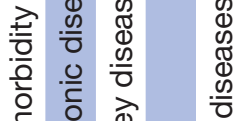




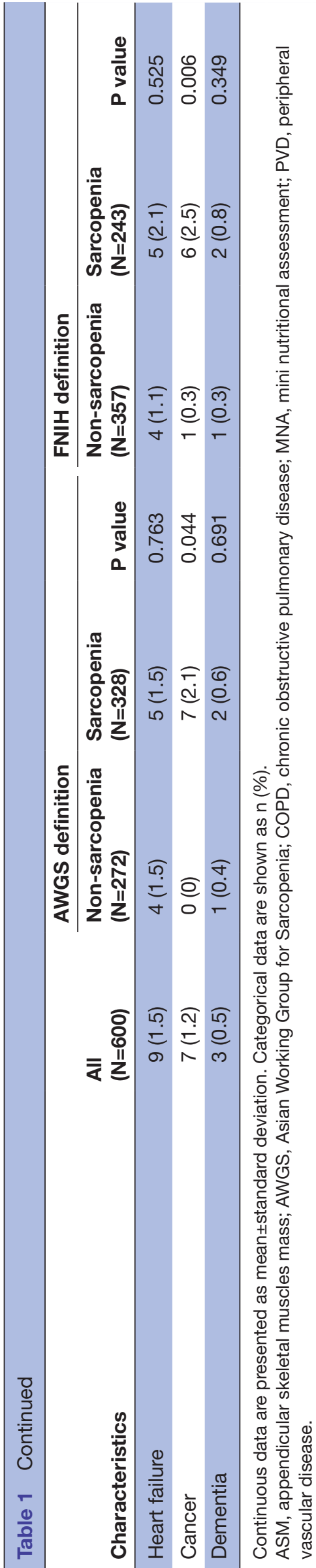

scarce. Therefore, this study aims to investigate the prevalence of sarcopenia and its associated factors in older patients attending geriatric clinics in Vietnam.

\section{METHODS}

Participants

Consecutive patients aged 60 years or above visiting the Outpatient Clinics of the National Geriatric Hospital in Hanoi, Vietnam, were recruited from January 2018 to October 2018 (online supplemental figure). Exclusion criteria were: (1) blind or deaf, (2) severe dementia or delirium, (3) pace-maker implanted and (4) unable to provide consent or refused to participate in the study.

Written informed consent was obtained from all participants.

\section{Sample size calculation}

The sample size was determined using a single population proportion formula: $n=Z_{1-\alpha / 2}^{2} \times\left[p \times(1-p) / d^{2}\right]$, with $\mathrm{n}=$ the required sample size, $\mathrm{Z}_{1-\alpha / 2}=1.96$ (with $\alpha=0.05 \%$ and $95 \%$ confidence interval), $\mathrm{p}=$ prevalence of sarcopenia in older patients and $\mathrm{d}=$ precision (assumed as $0.05)$. As there has been no study on sarcopenia in geriatric patients in Vietnam, we assumed $p$ to be $50 \%$. Therefore, the sample size for our study was calculated to be at least 384 participants.

\section{Data collection}

Data were collected from medical records and patient measurement. Information from medical records were extracted using a predefined data collection form, including demographic characteristics (age, sex, marital status, education level, rural/urban living) and medical history. Low education level was defined as a completion of primary school or lower. Comorbidities were recorded based on a predefined list, and a Charlson Comorbidity Index was also calculated for each participant. ${ }^{11}$ Nutritional status was assessed with the Mini Nutritional Assessment Short Form (MNA-SF) tool, the maximum score is 14 points and a total score $\leq 7$ points indicating a malnourished status. $^{12}$

Physical activity: The International Physical Activity Questionnaire (IPAQ) was used to measure physical activity level of the participants. ${ }^{13}$ The IPAQ included questions regarding vigorous and moderate activity, and walking in the previous 7 days. The metabolic equivalent task (MET, in minutes per week) of each category was calculated by multiplying the reported weekly minutes spent by the corresponding MET score ( 8 for vigorous activities, 4 for moderate activities and 3.3 for walking). Then the total score (in MET-minutes per week) was generated by summing these three activity categories (vigorous and moderate activity and walking). Physical activity levels were classified based on the total score as follows: low, <600 MET-minutes per week; moderate, 600-3000 MET-minutes per week and high, >3000 METminutes per week. ${ }^{13}$ 


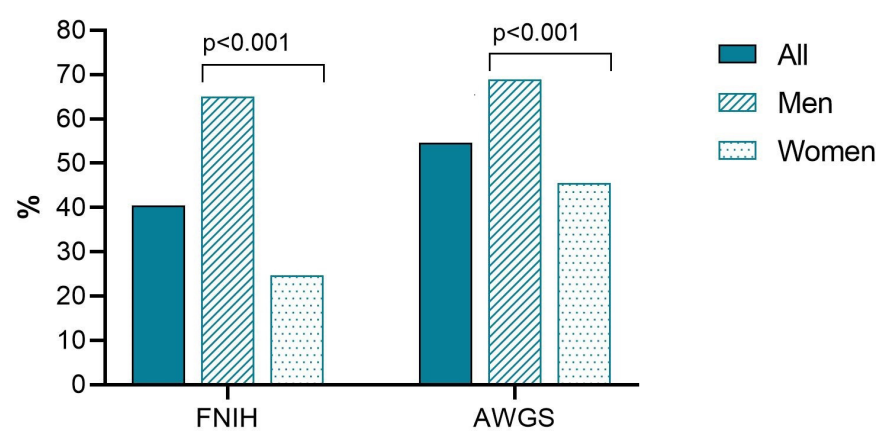

Sarcopenia criteria

Figure 1 The prevalence of sarcopenia in men and women. AWGS, Asian Working Group for Sarcopenia; FNIH, Foundation for the National Institutes of Health.

Weight (kg): Participants' weight were measured using an electronic scale (Electronic Body Scale TCS-200-RT), in standing position, minimal clothing and barefoot. Weight was recorded to the nearest $0.1 \mathrm{~kg}$.

Height $(\mathrm{m})$ : Participants were measured against a convenient flat wall. Participants were barefoot and height was recorded to the nearest $0.1 \mathrm{~cm}$.

Body mass index (BMI) was calculated as weight/ height ${ }^{2}\left(\mathrm{~kg} / \mathrm{m}^{2}\right)$ and was categorised into three groups underweight $(<18.50)$, normal $(18.50-24.99)$ and overweight $(\geq 25.00)$.

Grip strength $(\mathrm{kg})$ : Handgrip strength was measured using a dynamometer (Jamar Hydraulic Hand Dynamometer $5030 \mathrm{~J} 1$ made in USA). The participants were instructed to sit upright on a chair without armrest, with the elbows flexed at $90^{\circ}$. The measurement was conducted once in the right hand, and once in the left hand. The highest value of the two measurements was used for the analysis.

Muscle mass: Each participant received a whole body dual X-ray absorptiometry scan (DXA Medix DR C12, Mauguio, France) to measure regional lean mass $(\mathrm{kg})$, total body fat $(\mathrm{kg})$ and total body fat percentage (\%). Appendicular skeletal muscle (ASM, in $\mathrm{kg}$ ) was defined as the sum of the lean soft tissue masses of the arms and legs. ${ }^{14}$

\section{Sarcopenia definition}

In this study, sarcopenia was defined as low muscle mass plus low grip strength, ${ }^{2}$ using cut-points suggested by the Asian Working Group on Sarcopenia (AWGS 2019) and the Foundation for the National Institutes of Health (FNIH). ${ }^{1516}$

According to AWGS 2019, low muscle mass was defined with $\mathrm{ASM} / \mathrm{height}^{2}<7.0 \mathrm{~kg} / \mathrm{m}^{2}$ in men and $<5.4 \mathrm{~kg} / \mathrm{m}^{2}$ in women, and cut-points for low grip strength were $<28 \mathrm{~kg}$ in men and $<18 \mathrm{~kg}$ in women. ${ }^{16}$

According to FNIH, the recommended cut-points for low grip strength were $<26 \mathrm{~kg}$ in men and $<16 \mathrm{~kg}$ in women, and low muscle mass was defined as ASM adjusted for BMI $(\mathrm{ASM} / \mathrm{BMI})<0.789$ in men and $<0.512$ in women. ${ }^{15}$

\section{Statistical analysis}

Analysis of the data was performed using SPSS for Windows V.20.0 (IBM Corp., Armonk, New York, USA). Continuous variables are presented as mean $( \pm \mathrm{SD})$, and categorical variables as frequency and percentage. Comparisons between participants with and without sarcopenia were assessed using $\mathrm{X}^{2}$ tests for categorical variables and Student's t-tests for continuous variables. Two-tailed $p$ values $<0.05$ were considered statistically significant.

The kappa statistic was applied to investigate the agreement between the two sarcopenia definition. The degrees of agreement were defined as: poor (kappa coefficient $\leq 0.20)$, fair $(0.21 \leq$ kappa coefficient $<0.40)$, moderate $(0.41 \leq$ kappa coefficient $<0.60)$, good $(0.61 \leq$ kappa coefficient $<0.80)$ and very good $(0.81-1.00) .{ }^{17}$

Multivariate logistic regression was applied to identify associated factors for prevalence of sarcopenia. Univariate logistic regression was performed on sociodemographic factors (age, sex, education, marital status, living areas) and other potential factors that can be associated with sarcopenia based on the literature such as BMI, nutritional status, physical activity level, comorbidities and recent hospitalisation (in the past 12 months). Only variables that had a $p$ value $<0.20$ on univariate analysis were selected for multivariate analysis. A backward elimination method was applied and the final model retained variables significant at $\mathrm{p}<0.05$. All variables were examined for interaction and multicollinearity.

\section{Patient and public involvement}

Patients or the public were not involved in the design, or conduct, or reporting, or dissemination plans of our research.

\section{RESULTS}

There were 600 participants. They had a mean age of $70.0 \pm 8.0$ years and $60.8 \%$ were female. Overall, the most common chronic diseases were chronic kidney disease, hypertension, chronic lung disease and diabetes. Table 1 presents the general characteristics of the participants.

The prevalence of sarcopenia according to AWGS criteria was $54.7 \%$, and $40.5 \%$ according to FNIH. The

Table 2 The agreement between the AWGS and FNIH definitions of sarcopenia

\begin{tabular}{lll} 
& $\begin{array}{l}\text { Non-sarcopenic } \\
\text { (AWGS) } \\
\mathbf{N}=\mathbf{2 7 2}\end{array}$ & $\begin{array}{l}\text { Sarcopenic } \\
\text { (AWGS) } \\
\mathbf{N}=\mathbf{3 2 8}\end{array}$ \\
\hline $\begin{array}{l}\text { Non-sarcopenic (FNIH) } \\
\mathrm{N}=357\end{array}$ & 259 & 98 \\
$\begin{array}{l}\text { Sarcopenic (FNIH) } \\
\mathrm{N}=243\end{array}$ & 13 & 230 \\
\hline
\end{tabular}

AWGS, Asian Working Group for Sarcopenia; FNIH, Foundation for the National Institutes of Health. 
Table 3 Univariate logistic regression of potential factors associated with sarcopenia

\begin{tabular}{|c|c|c|c|c|}
\hline \multirow[b]{2}{*}{ Variables } & \multicolumn{2}{|l|}{ AWGS definition } & \multicolumn{2}{|l|}{ FNIH definition } \\
\hline & $\begin{array}{l}\text { Unadjusted ORs for } \\
\text { sarcopenia }(95 \% \mathrm{CI})\end{array}$ & $P$ value & $\begin{array}{l}\text { Unadjusted ORs for } \\
\text { sarcopenia }(95 \% \mathrm{Cl})\end{array}$ & $P$ value \\
\hline Male & 2.66 (1.89 to 3.76$)$ & 0.001 & 5.70 (3.98 to 8.16$)$ & $<0.001$ \\
\hline Low education & 1.99 (1.30 to 3.04$)$ & $<0.01$ & 2.85 (1.90 to 4.31$)$ & $<0.001$ \\
\hline $\begin{array}{l}\text { Living alone } \\
\text { (defined as single/divorced/widow) }\end{array}$ & 2.49 (1.59 to 3.89$)$ & $<0.001$ & 2.50 (1.65 to 3.80$)$ & $<0.001$ \\
\hline Rural living & 1.53 (1.11 to 2.12$)$ & 0.002 & 1.71 (1.23 to 2.38$)$ & 0.002 \\
\hline Underweight & 3.29 (1.94 to 5.59$)$ & $<0.001$ & 3.04 (1.90 to 4.87$)$ & $<0.001$ \\
\hline Hospitalisation in the last 12 months & 2.99 (2.11 to 4.25$)$ & $<0.001$ & 3.25 (2.30 to 4.59$)$ & $<0.001$ \\
\hline Malnourished & 10.37 (3.67 to 29.25$)$ & $<0.001$ & 8.45 (3.90 to 18.41$)$ & $<0.001$ \\
\hline \multicolumn{5}{|l|}{ Physical activity level } \\
\hline Charlson comorbidity index & $1.42(1.22$ to 1.65$)$ & $<0.001$ & $1.56(1.34$ to 1.81$)$ & $<0.001$ \\
\hline Chronic kidney disease & 2.45 (1.73 to 3.46$)$ & $<0.001$ & 2.41 (1.70 to 3.43$)$ & $<0.001$ \\
\hline Hypertension & 1.51 (1.10 to 2.09$)$ & 0.013 & 1.68 (1.21 to 2.33$)$ & 0.002 \\
\hline Chronic lung diseases (COPD/asthma) & 2.93 (2.09 to 4.9$)$ & $<0.001$ & 3.41 (2.42 to 4.80$)$ & $<0.001$ \\
\hline Diabetes & 1.05 (0.69 to 1.60$)$ & 0.821 & 1.39 (0.91 to 2.10$)$ & 0.124 \\
\hline PVD & 1.72 (0.86 to 3.41$)$ & 0.123 & 2.00 (1.03 to 3.83$)$ & 0.039 \\
\hline
\end{tabular}

Only variables with the number of cases $\geq 30$ were selected for univariate analysis.

AWGS, Asian Working Group for Sarcopenia; COPD, chronic obstructive pulmonary disease; FNIH, Foundation for the National Institutes of Health; PVD, peripheral vascular disease.

prevalence of sarcopenia was significantly higher in men compared with women (figure 1).

The Kappa coefficient value was 0.64 (95\% CI 0.58 to $0.70)$, indicating a moderate-good correlation between the two sarcopenia definitions. Table 2 shows the overlap between the two definitions.
Univariate logistic regression of potential associated factors for sarcopenia is presented in table 3 .

In multivariate logistic regression, age (adjusted OR $1.08,95 \%$ CI 1.05 to 1.11 ), male (adjusted OR $2.03,95 \%$ CI 1.29 to 3.21 ), underweight (adjusted OR 2.32, 95\% CI 1.22 to 4.41), being malnourished (adjusted OR 3.77,

Table 4 Factors associated with sarcopenia on multivariate logistic regression

\begin{tabular}{|c|c|c|c|c|}
\hline & \multicolumn{2}{|l|}{ Sarcopenia AWGS 2019} & \multicolumn{2}{|l|}{ Sarcopenia FNIH } \\
\hline & $\begin{array}{l}\text { Adjusted odds ratios } \\
(95 \% \mathrm{Cl})\end{array}$ & $P$ value & $\begin{array}{l}\text { Adjusted odds ratios } \\
(95 \% \mathrm{Cl})\end{array}$ & $P$ value \\
\hline Male & 2.03 (1.29 to 3.21$)$ & 0.002 & $6.78(4.12$ to 11.17$)$ & $<0.001$ \\
\hline Low education & - & - & 2.15 (1.27 to 3.63$)$ & 0.004 \\
\hline \multicolumn{5}{|l|}{ Physical activity levels } \\
\hline High (reference group) & 1 & $<0.001$ & 1 & $<0.001$ \\
\hline Moderate & 4.12 (2.34 to 7.26$)$ & & 6.27 (3.33 to 11.81$)$ & \\
\hline Low & 7.02 (3.52 to 14.01$)$ & & 10.75 (5.10 to 22.65$)$ & \\
\hline
\end{tabular}

AWGS, Asian Working Group for Sarcopenia; ; COPD, chronic obstructive pulmonary disease; FNIH, Foundation for the National Institutes of Health. 
95\% CI 1.19 to 11.91), chronic lung diseases (adjusted OR $3.48,95 \%$ CI 2.10 to 5.77 ) and lower physical activity were significantly associated with sarcopenia defined by AWGS criteria. Similarly, the significantly associated factors with sarcopenia defined by FNIH criteria were age, male, low education, being malnourished, chronic lung diseases and lower physical activity level (table 4).

\section{DISCUSSION}

In this study, in 600 older community dwellers attending outpatient clinics at a geriatric hospital in Vietnam, the prevalence of sarcopenia was quite high and varied according to the criteria used. There was a moderategood correlation between the two AWGS and FNIH definitions, and a higher prevalence of sarcopenia was identified using AWGS criteria (low muscle mass defined as ASM adjusted for height) compared with FNIH criteria (low muscle mass defined as ASM adjusted for BMI) ( $54.7 \%$ vs $40.5 \%$, respectively). Older age, male, lower physical activity level, a malnourished status defined by MNA-SF and chronic lung disease were consistently associated with sarcopenia defined by either AWGS 2019 or FNIH.

Our findings were in line with previous studies in Asia, which showed that about half of geriatric patients were diagnosed with sarcopenia. ${ }^{56}$ However, compared with several other studies in geriatric outpatients in Western countries, the prevalence of sarcopenia in our study was higher. In a study in 298 older patients attending geriatric clinics in Spain, the prevalence of sarcopenia defined by the criteria of the European Working Group on Sarcopenia in Older People (EWGSOP) was $19.1 \%{ }^{18}$ In another study in 189 older outpatients in Denmark, the prevalence of sarcopenia (defined by EWGSOP) was 26\%. ${ }^{19}$ The high prevalence of sarcopenia in our study may be explained by the fact that our study population were old, (mean age 70 , with $15 \%$ were 80 or older) and had high prevalence of chronic diseases. Several studies have reported higher sarcopenia prevalence in groups of older patients with chronic illnesses, $15 \%-50 \%$ in patients with cancer, $30 \%-45 \%$ with liver failure, $15 \%-33 \%$ with diabetes and $60 \%-70 \%$ for critically ill patients in the intensive care unit. ${ }^{20}$

Interestingly, in our study, male was associated with increased risk of sarcopenia. Previous studies showed that prevalence of sarcopenia was significantly higher in male compared with female. ${ }^{21}{ }^{22}$ There has been evidence that the rate of skeletal muscle loss was accelerated in men compared with women. ${ }^{23}{ }^{24}$ Sex hormones may contribute to this difference. At advanced stage of ageing, there is a substantial decrease of testosterone, a potent anabolic factor promoting the synthesis of skeletal muscle protein and muscular regeneration, in men. ${ }^{25} 26$

The findings from this study suggest that more effort is needed to increase awareness of sarcopenia and to implement sarcopenia screening in older patients in Vietnam, particularly in patients with chronic lung diseases. The relationship between lung function and sarcopenia was reported in several studies. In a study in 1907 participants in Korea, participants with low muscle mass had low forced vital capacity (FVC) or low forced expiratory volume in 1s (FEV1) values. ${ }^{27}$ In another study in 605 communitydwelling older healthy women in Korea, hand grip strength was positively associated with pulmonary function. ${ }^{28}$ There are several mechanisms that can explain the association between sarcopenia and pulmonary dysfunction. Chronic systematic inflammation, which is a common factor in chronic lung diseases, can cause myocyte apoptosis and muscle proteolysis. ${ }^{29}{ }^{30}$ Ventilation-perfusion mismatch and reduced physical activity in chronic lung disease may lead to poor muscular oxygenation. ${ }^{31}$ In addition, respiratory skeletal muscles, including the diaphragm, are also affected by the generalised sarcopenic process as other skeletal muscles. ${ }^{32}$

Our findings also suggest that older patients should receive assessments of nutritional status and physical activity routinely. There was a high prevalence of physical inactivity and malnutrition in Vietnam. ${ }^{10}$ According to the International Clinical Practice Guidelines for Sarcopenia, the prescription of resistance-based physical activity and conditionally recommend protein supplementation/a proteinrich diet were strongly recommended to treat sarcopenia. ${ }^{4}$

This study has several limitations. First, it was conducted in the geriatric clinics, where the prevalence of sarcopenia is likely to be higher than in the community. Second, this study was conducted at a single hospital in Vietnam, which may not be representative for all older patients in Vietnam. Therefore, results should be cautiously interpreted and generalised to all older patients.

\section{CONCLUSION}

In this study in older patients attending geriatric clinics in Vietnam, the prevalence of sarcopenia was high. Further studies are needed to examine the impact of sarcopenia on adverse outcomes in this population.

Acknowledgements We are deeply grateful to all participants who gave their time to participate in this study. We thank Mrs Nguyen Lan Anh for the support with inputting of the data.

Contributors TNN, ATN, TP, TXN, HTTN, TNN, TTHN and HTTV conceived the study, participated in its design and implementation and wrote the manuscript. TNN, TNN and HTTV analysed the data. All the authors read and approved the final manuscript.

Funding The authors have not declared a specific grant for this research from any funding agency in the public, commercial or not-for-profit sectors.

Competing interests None declared.

Patient and public involvement Patients and/or the public were not involved in the design, or conduct, or reporting, or dissemination plans of this research.

Patient consent for publication Not required.

Ethics approval The study was approved by the Ethics Committee of the National Geriatric Hospital Review Board, Hanoi, Vietnam, (Reference Number: 1235/IRB).

Provenance and peer review Not commissioned; externally peer reviewed.

Data availability statement The data that support the findings of this study are available from the corresponding author upon reasonable request.

Open access This is an open access article distributed in accordance with the Creative Commons Attribution Non Commercial (CC BY-NC 4.0) license, which 
permits others to distribute, remix, adapt, build upon this work non-commercially, and license their derivative works on different terms, provided the original work is properly cited, appropriate credit is given, any changes made indicated, and the use is non-commercial. See: http://creativecommons.org/licenses/by-nc/4.0/.

\section{ORCID iDs}

Tu Ngoc Nguyen http://orcid.org/0000-0002-8836-8920

Huyen Thanh Thi Vu http://orcid.org/0000-0002-3132-3801

\section{REFERENCES}

1 Morley JE, Anker SD, von Haehling S. Prevalence, incidence, and clinical impact of sarcopenia: facts, numbers, and epidemiologyupdate 2014. J Cachexia Sarcopenia Muscle 2014;5:253-9.

2 Chen L-K, Liu L-K, Woo J, et al. Sarcopenia in Asia: consensus report of the Asian Working group for sarcopenia. J Am Med Dir Assoc 2014;15:95-101.

3 Anker SD, Morley JE, von Haehling S. Welcome to the ICD-10 code for sarcopenia. J Cachexia Sarcopenia Muscle 2016;7:512-4.

4 Dent E, Morley JE, Cruz-Jentoft AJ, et al. International clinical practice guidelines for sarcopenia (ICFSR): screening, diagnosis and management. J Nutr Health Aging 2018;22:1148-61.

5 Yoshimura Y, Wakabayashi H, Bise T, et al. Prevalence of sarcopenia and its association with activities of daily living and dysphagia in convalescent rehabilitation ward inpatients. Clin Nutr 2018;37:2022-8.

6 Shiraishi A, Yoshimura Y, Wakabayashi H, et al. Prevalence of stroke-related sarcopenia and its association with poor oral status in post-acute stroke patients: implications for oral sarcopenia. Clin Nutr 2018;37:204-7.

7 Dodds RM, Granic A, Robinson SM, et al. Sarcopenia, longterm conditions, and multimorbidity: findings from UK Biobank participants. J Cachexia Sarcopenia Muscle 2020;11:62-8.

8 Feigin VL, Lawes CMM, Bennett DA, et al. Worldwide stroke incidence and early case fatality reported in 56 population-based studies: a systematic review. Lancet Neurol 2009;8:355-69.

$9 \mathrm{Ha} \mathrm{NT}$, Le NH, Khanal V, et al. Multimorbidity and its social determinants among older people in southern provinces, Vietnam. Int $J$ Equity Health 2015;14:50.

$10 \mathrm{MOH}$. National Survey of Risk Factors of NCDs in Vietnam, . Ministry of Health, Hanoi, Vietnam 2016.

11 Charlson ME, Pompei P, Ales KL, et al. A new method of classifying prognostic comorbidity in longitudinal studies: development and validation. J Chronic Dis 1987;40:373-83.

12 Kaiser MJ, Bauer JM, Ramsch C, et al. Validation of the mini nutritional assessment short-form (MNA®-SF): a practical tool for identification of nutritional status. The Journal of Nutrition, Health and Aging 2009;13:782-8.

13 Tran DV, Lee AH, Au TB, et al. Reliability and validity of the International physical activity Questionnaire-Short form for older adults in Vietnam. Health Promot J Austr 2013;24:126-31.
14 Heymsfield SB, Smith R, Aulet M, et al. Appendicular skeletal muscle mass: measurement by dual-photon absorptiometry. Am J Clin Nutr 1990;52:214-8.

15 Studenski SA, Peters KW, Alley DE, et al. The FNIH sarcopenia project: rationale, study description, conference recommendations, and final estimates. J Gerontol A Biol Sci Med Sci 2014;69:547-58.

16 Chen L-K, Woo J, Assantachai P, et al. Asian Working group for sarcopenia: 2019 consensus update on sarcopenia diagnosis and treatment. J Am Med Dir Assoc 2020;21:300-7.

17 Zhu Y, Liu Z, Wang Y, et al. Agreement between the frailty index and phenotype and their associations with falls and overnight hospitalizations. Arch Gerontol Geriatr 2016;66:161-5.

18 Cuesta F, Formiga F, Lopez-Soto A, et al. Prevalence of sarcopenia in patients attending outpatient geriatric clinics: the ELLI study. Age Ageing 2015;44:807-9.

19 Christensen MGet al. Prevalence of sarcopenia in a Danish geriatric out-patient population. Dan Med J 2018;65.

20 Peterson SJ, Braunschweig CA. Prevalence of sarcopenia and associated outcomes in the clinical setting. Nutr Clin Pract 2016;31:40-8.

21 Du Y, Wang X, Xie H, et al. Sex differences in the prevalence and adverse outcomes of sarcopenia and sarcopenic obesity in community dwelling elderly in East China using the AWGS criteria. BMC Endocr Disord 2019;19:109.

22 Kim TN, Yang SJ, Yoo HJ, et al. Prevalence of sarcopenia and sarcopenic obesity in Korean adults: the Korean sarcopenic obesity study. Int J Obes 2009;33:885-92.

23 Zamboni M, Zoico E, Scartezzini T, et al. Body composition changes in stable-weight elderly subjects: the effect of sex. Aging Clin Exp Res 2003;15:321-7.

24 Gallagher D, Ruts E, Visser M, et al. Weight stability masks sarcopenia in elderly men and women. Am J Physiol Endocrinol Metab 2000;279:E366-75.

25 Anderson LJ, Liu H, Garcia JM. Sex differences in muscle wasting. Adv Exp Med Biol 2017;1043:153-97.

26 Yamada M, Nishiguchi S, Fukutani N, et al. Prevalence of sarcopenia in community-dwelling Japanese older adults. J Am Med Dir Assoc 2013;14:911-5.

27 Choe EK, Lee Y, Kang HY, et al. Association between CT-Measured abdominal skeletal muscle mass and pulmonary function. J Clin Med 2019;8. doi:10.3390/jcm8050667. [Epub ahead of print: 12 May 2019].

28 Son D-H, Yoo J-W, Cho M-R, et al. Relationship between handgrip strength and pulmonary function in apparently healthy older women. J Am Geriatr Soc 2018;66:1367-71.

29 Bano G, Trevisan C, Carraro S, et al. Inflammation and sarcopenia: a systematic review and meta-analysis. Maturitas 2017;96:10-15.

30 Byun MK, Cho EN, Chang J, et al. Sarcopenia correlates with systemic inflammation in COPD. Int $J$ Chron Obstruct Pulmon Dis 2017;12:669-75.

31 Lopes AJ, Mafort TT. Correlations between small airway function, ventilation distribution, and functional exercise capacity in COPD patients. Lung 2014;192:653-9.

32 Greising SM, Mantilla CB, Gorman BA, et al. Diaphragm muscle sarcopenia in aging mice. Exp Gerontol 2013;48:881-7. 